\title{
From Subversive Strategies to Women's Empowerment
}

Feminist Humour in Quino's Mafalda and Flavita Banana's Vignettes

\author{
Orsolya ANDRÁS \\ Department of Hungarian Literary Studies \\ Babeş-Bolyai University (Cluj-Napoca, Romania) \\ orsolya.andras@gmail.com
}

\begin{abstract}
This paper discusses the potential of humour in understanding and deconstructing gender inequalities and analyses the representation of some feminist issues in two Spanish-speaking artists' works. The theoretical framework explores the interpretation of laughter by feminist authors as well as different approaches of feminist humour in the context of cultural studies. The definition of humour presented here is that it can function as an open space where we can safely observe social structures and experiment with our imagination. In the second part of the paper, some examples from Quino's comic series Mafalda and Flavita Banana's vignettes are discussed. In the interpretation of these artworks, the paper highlights two types of feminist discourse and, specifically, of feminist humour. The first one, exemplified through Quino's Mafalda, uses subversive strategies in order to expose social injustice and sexism. However, these strategies are sometimes still not able to propose an alternative to the existing status quo. The second type of feminist discourse and humour, characteristic of Flavita Banana's art, also starts from depicting the consequences of patriarchy. However, her approach is not only subversive but also empowering and liberating, constructing a safe imaginative space through humour.
\end{abstract}

Keywords: feminism, humour, comics and vignettes, subversive discourse, imagination

\section{Theoretical framework}

\subsection{Laughter and feminism: Different approaches}

Humour is deeply rooted in our existence in groups and communities. We hardly ever laugh alone, and, even if we do, our laughter usually starts with a social interaction 
or an impulse which makes us realize something about ourselves and the way we perceive the world. Laughter as shared joy can give us a sense of belonging, to a certain level of complicity, such as in the case of so-called "inside jokes" or moments of happiness amplified by the presence and participation of others. At the same time, laughter which expresses mockery, malicious joy, or envy is part of the most humiliating experiences, resulting in exclusion, separation, and loneliness. Humour is, by consequence, something we can experience when defining group boundaries.

If we choose to view gender in a paradigm of binarities, and we are attached to traditional gender roles when we determine our identity - and through identity we define our affinity to a certain group -, we perpetuate these exclusive boundaries in gender-related humour. In this context, there can be two possible extremes of humour: one marked by exclusion and antagonism and the other one by belonging and solidarity or complicity. In the first part of this paper, the interpretation of laughter by feminist authors as well as different definitions of feminist humour in the context of social sciences and cultural studies will be presented. Through this literature review, the paper aims to demonstrate that these two mentioned extremes of humour are sometimes the two faces of the same coin. Hopefully, at the end of the literature review, we can find a position between these extremes, to observe both of them with attention and question the system that produced our binary-bound thinking. A new definition is going to be proposed, according to which humour can function as an open space where we can safely observe social structures and experiment with our imagination. This approach is introduced in order to deconstruct gender and transgress the binarities of male vs. female, misogynist humour vs. male-mocking humour. After the theoretical part, the paper will focus on the works of two Spanish-speaking artists, Quino's comic series Mafalda and Flavita Banana's vignettes, and analyse the discourses of humour they use and activate.

Feminist humour, or the importance attributed to laughter in the deconstruction of power relations between the genders, is not a new topic at all. In her book about $18^{\text {th }}-19^{\text {th }}$-century female authors, Laughing Feminism (1998), Audrey Bilger dedicates a chapter to the role of laughter in the interaction between the genders as described by Mary Wollstonecraft as well as to her definition of feminist humour. The writer and philosopher, considered one of the pioneer feminist thinkers, whose work is crucial for the first-wave feminism, paid special attention to laughter. According to Bilger, Wollstonecraft's iconic work, A Vindication of the Rights of Woman (1796), makes the difference between misogynist laughter, which she wants to silence, and the laughter caused by identifying and ridiculing it, addressing an attack on the stereotypes behind it. In contrast to this powerful, bold, or even aggressive laughter, Wollstonecraft refuses the smile of complacency, often expected from women according to the traditional gender roles (Bilger 1998: 42-43). Here, one can clearly observe that humour serves as a means to define group boundaries; 
to put it practically: as feminist women, we will not laugh at the misogynist jokes they laugh at but at them and their limited thinking, which we refuse.

Second-wave feminism takes distance from this antagonistic perspective focusing on men seen as "enemies", and this is reflected in its interpretation of humour. As Leigh Marlowe formulates it, “[f]eminists want to 'pick up' women, not 'put down' men” (qtd. in Mackie 1990: 21). Obviously, feminists will always fight against misogyny on the comedy scene, such as sexist or rape jokes, as Kira Cochrane states and exemplifies in All the Rebel Women (2013). However, the main objective becomes to define women's voices, to make them heard, to liberate and activate women's writing, women's laughter. In her essay The Laugh of the Medusa (1976), Hélène Cixous associates women's laughter with unsuppressed rage, untamed energy, free expression, with breaking the mould and deconstructing stereotypes. She reinterprets the Greek myth of Medusa, originally a woman absurdly punished for having been raped. Cixous sees in this character a wonderful empowered woman, whose voice must be heard: "You only have to look at the Medusa straight on to see her. And she's not deadly. She's beautiful and she's laughing” (Cixous, 1976: 885). Cixous's essay can be interpreted as an intense and explosive flow of rage, strength and courage, which her female readers acutely need in order to create in a world dominated by patriarchy. However, we cannot gloss over Cixous's aggressiveness and dominance, as in the first paragraphs of her essay she repeatedly uses "must" and "must not". This is not the aim of any empowering discourse, to enforce one's ideas in the name of emancipation, because an emancipatory context lets everyone's voice heard.

\subsection{Definitions of feminist humour}

This is why feminist theoreticians can also take distance from both the male and the female perspective and try to transgress the oppositions, also leaving behind the binarity of gender. Instead, some authors focus on the social system as a whole, and this enables a more distant analysis of the power relations and the role of humour. In Who's Laughing Now? The Role of Humour in the Social Construction of Gender (1990), Marlene Mackie attributes two different functions to humour: it can either confirm the patriarchal status quo or can be subversive and rebellious, challenging the established order. The author generalizes, takes distance, and tells much more than just positioning women against men, because the issue itself is also more complex. One has to look at all layers of the social establishment, which are, of course, interdependent, arriving at an intersectional feminist approach. For instance, patriarchy is not something that would only harm cis-heterosexual women, and it is not less damaging for cis-heterosexual men; gender is not even as limited as these two categories and cannot be thought of as binary; it also cannot be separated from the factors of international relations and world economy. Attuned 
to the second-wave feminist discourse, Mackie defines gender as a social construct (1990: 12), that is, separated from biological sex and connected to the ideas created and perpetuated by society.

This widespread conception was further explored, and humour was defined as a way of gender deconstruction, for example, in Sabah Al Mushtaq's Humour: As a Tool for Gender Construction and Deconstruction (2017), or as a means to dismantle stereotypes and prejudices. Mushtaq focuses on the ambiguity of humour, which, according to her, allows us to discuss taboo topics or approach power relations in a critical, even playful way (2017: 33). She defines feminist humour as having an emancipatory potential, building the sense of group identity and solidarity and resistance to social control (Mushtaq 2017: 34). However, she mentions that in communication the parts engaged in a conversation should define together if the interaction is in "serious mode" or "humorous mode" (Mushtaq 2017: 33). The safe space of ambiguities can, therefore, be accessed with consent from all parts - this is why group identity and solidarity in these terms is not exclusive but inclusive -, and it is also open to everyone who is ready to question and let go of their own preconceptions. This way, humour can help us leave behind the binarity of gender and gender roles, the binarity of values, and enter a free space of discussion with infinite opportunities.

Jo Anna Isaak considers laughter a metaphor for the transformation of society and culture: "[l]aughter can also provide an analytic for understanding the relationships between the social and the symbolic while allowing us to imagine these relationships differently" (qtd. in Bilger 1998: 39). This statement resonates with the definition of humour proposed in this paper - namely, as a safe space which allows us to observe social structures rather than to take them for granted. In this context, imagination seems to play a crucial role. When we use humour in our communication, we allow our partner not to take us too seriously (when we use humour, we can almost always say: it was only a joke). When we, on the other hand, do not take ourselves too seriously, we enter a radically free space, where we observe the current structures of our society just as they are, as structures, and not as unchangeable rules. We are in an ambiguous space, and, by taking distance from the established power relations, we are free to imagine something completely new, to rethink the world we inhabit.

Hopefully having highlighted the potential of humour for an empowering and emancipatory discussion of gender-sensitive topics, the paper will focus in the following on the examples selected from Quino's and Flavita Banana's work. Both authors deal with the problem of gender stereotypes and inequalities, using different discourses of humour. This paper asks to what extent and how these comic strips and vignettes use the imaginative and safe space of humour and whose voices they make heard. Before analysing some examples from Quino's and Flavita Banana's work, a brief outline of some current feminist issues present in the public space 
in Spanish-speaking countries will be given in order to explain the popularity of both artists and the background of the decision to discuss their work. Afterwards, the specificities of comics and vignettes in the context of feminist political direct action will be discussed.

\section{Contextualization of the selected artworks}

\subsection{Current feminist issues in some Spanish-speaking countries}

Joaquín Salvador Lavado Tejón aka Quino is from Argentina, and his iconic comic series Mafalda was published between 1964 and 1973 in different periodicals. Although his work is not contemporary, Mafalda is still very popular in Spanishspeaking countries, especially among readers who are politically active. The comic series addresses multifarious social issues, but the strips with feminist content seem to gain topicality in Latin America since the problems represented by Quino have not disappeared after the second wave of the feminist movement, which was at its peak in his lifetime. In Argentina, the feminist movement Ni una menos [Not one [woman] less - making reference to the main goal, to stop femicides] started with massive demonstrations in 2015 and spread through many Latin American countries. This initiative can be described as an intersectional feminist movement, involving the fight for equality in all domains: reproductive rights (legalization of abortions), equal salaries, LGBTQ+ rights, criminalizing gender-based violence.

Flavia Álvarez-Pedrosa, aka Flavita Banana, is a young illustrator living in Barcelona. Her Instagram account @flavita.banana has 611,000 followers, and she has posted vignettes here since 14 November 2014. Her work has also been published in Spanish newspapers El País, Revista Mongolia, El Salto, and S Moda as well as in books of which she is either individual author or co-author. The empowering feminist message of her work becomes politically relevant if one considers some recent events in Spain. The shocking case of the 2016 gang rape known as $L a$ Manada [The Wolf Pack - the case being named after the WhatsApp group which contained the plans and discussions of the five criminals], and especially the unfair and sexist way in which justice handled it, started a wave of indignation and gave the impulse to several feminist protests. Today, fighting machismo, gender-based discrimination, and domestic violence represent priorities in Spain both on the political agenda and in the public discourse. These two cases are only examples for the rise of powerful feminist discourses in Spanish-speaking countries. Even if, or especially because, they concern very serious problems, we cannot neglect the role of humour in them. 


\subsection{Comics and vignettes: From popular culture to critical thinking}

As mentioned before, humour allows us to take ourselves less seriously - which obviously does not mean neglecting severe social problems, but this attitude can activate the potential of our imagination and start social change. As Marlene Mackie points it out in her quoted essay, sociologists and scholars of gender studies ought to take laughter, humour, and fun very seriously (1990: 11). This is especially true for popular genres such as comics and vignettes, which reach many readers through printing and online press. It would be anachronistic to exclude popular culture from our research, especially in the era of social media, if we want to understand the impact of humour on society.

Inger-Lise Kalviknes Bore, Anne Graefer, and Allaina Kilby analyse the appearance in social media of some banners from Women's March 2017. The three authors highlight an affective turn in social sciences, based on the fact that media content is not simply decoded by people as neutral information but is also a matter of emotional attachments, feelings, and embodied experience. They emphasize the affective potential of humour and the role of emotion in active citizenship - for example, they see anger as an empowering force and energy (Kalviknes Bore-Graefer-Kilby 2017: 529-530). Messages which are easily spread through social media, especially those containing images, such as comics and vignettes, are definitely activating emotions. Through the simple yet intense representation of social problems, as in the case of Quino's and Flavita Banana's work, these are also able to activate the critical thinking of the readers. Furthermore, as the three authors demonstrate, social media is able to mobilize feminists who are physically apart but emotionally close and offer them the sense of community (Kalviknes Bore-Graefer-Kilby 2017: 530).

The ironic or sarcastic vignettes perform an accessible representation of burning issues, and, as Kira Cochraine explains, in the case of feminism, this kind of humour helps to involve young women in activism. She defines humour as a political tactic that also helps activists facing depressing issues to stay focused and optimistic (Cochrane 2013).

\section{Analysis of the selected artworks}

In the following, the selected examples from Quino's and Flavita Banana's works will be presented. In the analysis, two different approaches to the gender-related issues will be highlighted. The first one, which I mean to exemplify through Quino's Mafalda, uses subversive strategies in order to expose social injustice and sexism. Among such tools, this paper focuses on the protagonist's perspective and the little child's power to unmask the truth. Although this discourse is able to represent the social situation, it sometimes falls into one of the extremes mentioned 
in the theoretical introduction, and therefore cannot transgress binary thinking nor properly use the imaginative space of humour in order to offer an alternative to the existing status quo.

The second type of feminist discourse and humour, which seems to be characteristic of Flavita Banana's art, also starts from depicting the consequences of patriarchy, but it goes a significant step further. Namely, the artist does not present women as victims, rather as independent beings, highlighting their agency, which makes her approach not only subversive but also empowering and liberating. Her imaginative art opens a dialogue and constructing alternatives to the current situation.

\subsection{Mom, look: The patriarchy's naked! - Subversive humour in Quino's Mafalda}

Quino's Mafalda series started in 1964, originally as advertisement for electrical domestic appliances. Soon it grew into a complex portrait of the Buenos Aires middle class and the social changes of the 1960s and 1970s, being published in the newspapers Primera Plana, El Mundo, and Siete días until 1973. The Mafalda strips appeared in collections in many Spanish-speaking countries and were translated into different languages. Franco Marchionni and Romina Sales describe the major historical events, social, political, and economic transformations which they consider emblematic for the background of Mafalda such as the success of The Beatles, Franco's dictatorship in Spain, the US embargo on Cuba, the baby boom, the anxiety caused by nuclear weapons, the raise of anti-racist and postcolonial discourses, the Vietnam war, the hippie movement, the establishment of consumerist society, and the spreading use of television (2012: 6). Quino tries to observe all these events and phenomena with critical distance, which is the source of his humour.

His main character is a little girl called Mafalda, characterized - according to David William Foster - by an "acute sensitivity to the world around her" (2004: 498). Foster points out that Mafalda always seems more mature than her age, giving surprisingly sharp comments to the adults, while the rest of the comic's universe is constructed with great accuracy - this contradiction is coined by Foster as "judicious inverisimilitude" (2004: 498). In her book about the social and political history of Mafalda, Isabella Cosse also focuses of the protagonist's perspective and the child's voice, which is supposed to mellow and ease the often very sharp criticism (2014: 50). According to Cosse, the character Mafalda defies both gender and generation stereotypes: she is the one who confronts her parents with unpleasant truth, and not vice versa. She is a little girl speaking and behaving as little girls "shouldn't” (Cosse 2014: 44). Among many different social issues, Mafalda approaches the transformation of gender roles. Isabella Cosse also mentions that Mafalda questions the female roles of her mother, representing the traditional ideal of a spouse (2014: 48). The author describes 
Mafalda's implacable logic, typical of children, as a means to unmask the adults' condition (Cosse 2014: 49). This is where the mentioned free imaginative space of humour can come into being, although, as we will see, not to a full extent.

The examples selected from the comic series are scenes of Mafalda and Raquel, her mother and Susanita, her playmate. These sequences both represent the little girl's mature thinking and her agency similar to the child's one in Hans Christian Andersen's famous tale The Emperor's New Clothes. She is able to rapidly and sharply unmask many problems concerning Argentinian middle-class women's condition in the 1960s and 1970s. This kind of humour can have a bitter taste to the reader, but it can definitely open their eyes to the social reality.

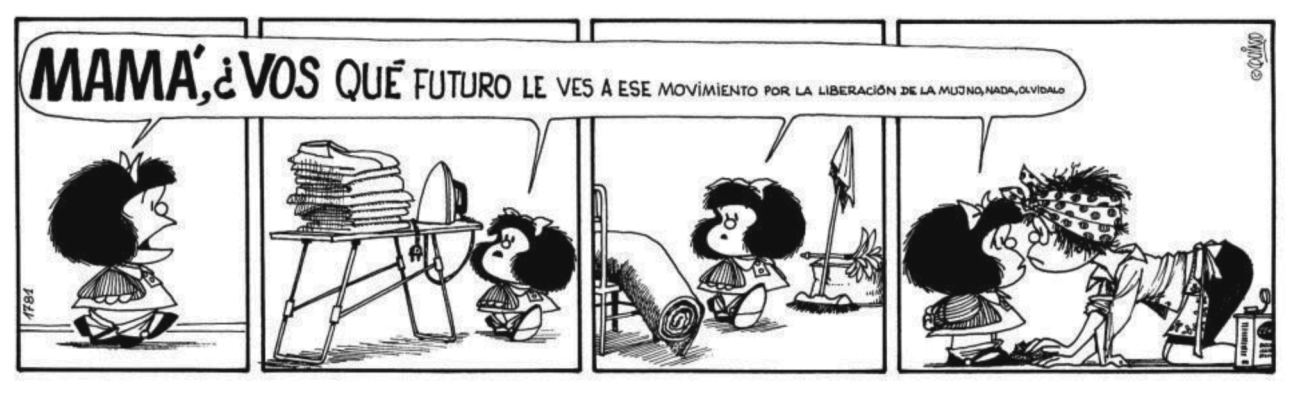

Source: Quino 1997, no page number

Figure 1. Mom, what do you think about the future prospects of this movement for the liberation of wome... nothing, never mind.

Second-wave feminist ideas started to be widely spread in the 1960s and 1970s. Since the action of the comic strips is taking place during these years, the main character is obviously curious about the new phenomena, as we know Mafalda as a girl who listens to the news and is always up-to-date with what is going on in the world. Here, the source of the bitter humour is the interaction between the picture and the text as well as the graphical structure of the latter. The reader follows Mafalda's gaze through the family's apartment, looking at the props of chores (ironing, cleaning), while the words about change, future, and feminism literally sink and disappear between these objects, which makes Mafalda avoid the enthusiastic discussion she wanted to start with her mother about women's empowerment. In the final scene, Raquel appears dressed for cleaning, with messy hair and an exhausted facial expression. Here, a radio is part of the scene, but it is half hidden and in a peripheral position, expressing Quino's irony and bitter caricature of the discrepancy between militant activism and the daily life of many women, dominated by domestic oppression. Mafalda's shocked and sad face at the end is exactly the mirror of this dissonance. Her and Raquel's face almost touch, expressing the differences and tensions between two very different generations, the moment of transformation in society, which is everything but easy. 

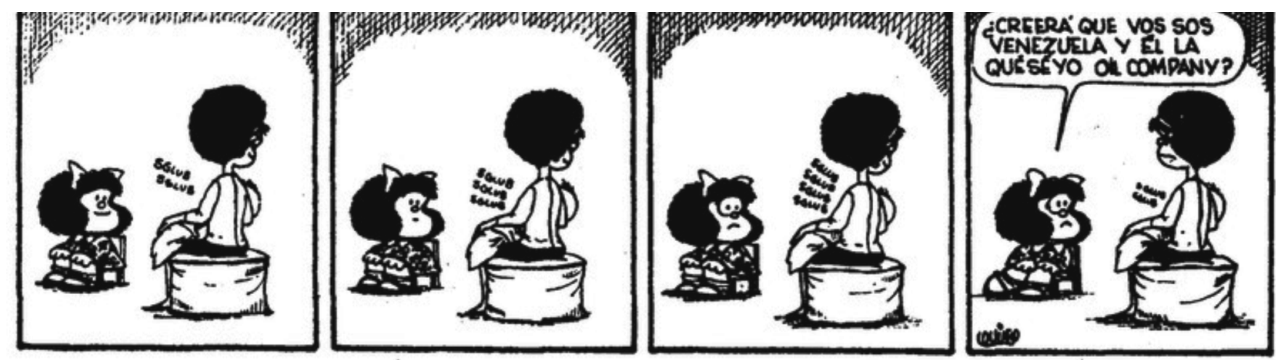

Source: Quino 1997, no page number

Figure 2. Might he think that you are Venezuela and he is the I-don't-know-which Oil Company?

As David William Foster mentions it, in Mafalda, Quino deals with social inequity and Argentina's foreign exploitation, the loss of national identity (2004: 502). The second example establishes a connection between women's oppression and the global social and economic injustice. Mafalda observes her mother breastfeeding her new-born brother, Guille. Initially, her face is calm, her expression shows affection for her sibling, and her mother smiles lovingly at the infant. However, later on, Mafalda starts to think about the baby's greed (suggested by the frequency of onomatopoeias) and shocks her mother with a question.

The comparison between the woman fulfilling reproductive tasks and the country being exploited by a great power (in this case, a reference to the relation between Venezuela and the US is made) would generate very intense discussions even today. The definition of motherhood is an overly sensitive topic for feminists. It can be seen as the supreme manifestation of unconditioned love, as sacrifice, as a complex relationship, as a spiritual experience. The problems of post-partum depression, emotional labour, and the incredible power of mothers to overcome difficulties often at the cost of their own mental and physical health are personal experiences which should be approached with tactfulness and without any judgement. What is, however, certain: women are generally more engaged in the raising of children than men, and this is also true for chores, reproductive work, unpaid and informal labour. Women, on the global labour market, generally give more of their time and resources than they get, at least economically. In this sense, the comparison unmasks the global inequity with negative effects on developing countries and women. The bitter taste provoked by this strip is only increased by the focus on the material, and not the emotional aspects, being an example of cruel humour. 

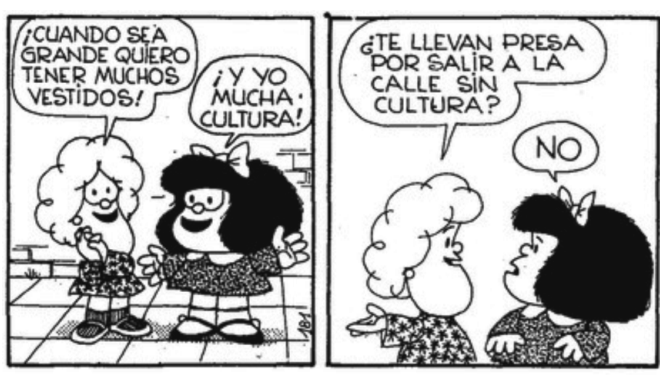

Figure 3. 1. - When I grow up, I want to have a lot of dresses! - And me, a lot of knowledge! 2. - Do you get arrested if you go out without knowledge? - No. 3 . - Well, try going out without a dress!... 4. It is totally sad to have to hit someone who is right.

Mafalda is a little girl who adores going to school, learning, and staying informed. She also regrets that her mother did not graduate from the university she started to attend. Culture as one of her most important values clashes with her playmate's, Susanita's preference for material values and traditional female roles, as she dreams in many strips to become a mother and wife. In the third example from the comic series, the two girls compare their future perspectives. Susanita demonstrates the primacy of her desires through a practical argument, and Mafalda, in spite of her aggressive reaction, deep down has to accept that she is right in that moment, at that place.

This example illustrates very clearly my conclusion about the feminist content of Quino's Mafalda. The artist manages to draw some attention to social problems relevant from a feminist point of view, through the child's perspective and subversive approach, offering the possibility for the reader to question the takenfor-granted system and reality around them. However, the characters do not appear in an empowered position, and they do not manage to overcome or transgress the framework of the social structures. Showing the problem, exposing sexism, unmasking traditional gender roles which degrade women to servants, addressing the lack of access to education - all this is very important, but not enough. Quino's representation of women is on the fine line between the bitter realization of the problem and cynical, misogynist laughter, which can be humiliating for many women. It is also emblematic that in both examples where Raquel appears she remains silent, a passive and voiceless character, which is not an empowered position at all. Looking back at Marlene Mackie's quoted categorization, according to which humour can either consolidate or subvert the status quo, here, Quino's humour is clearly not sufficient to completely transgress the existing gender inequalities and stereotypes. 


\subsection{Between vulnerability and empowerment - Flavita Banana's vignettes}

Flavita Banana has a clearly expressed feminist attitude, as she states in an interview: "We need to fight by the means of our own example, we need to carry on with our lives as we like it, and, above all, we need to claim equality of rights" (García Navarro 2018: 113). Flavita Banana's art is an empowering sort of humour, raising her voice against sexism with scepticism and rebel approach (Blanco Martínez 2017: 22).

Flavita Banana's humour can be considered feminist in an empowering sense. She is able, like Quino, to show the inequalities produced by patriarchy in a sarcastic way, but she goes a step further and puts female characters in empowered positions, highlighting their agency, independence, and different strategies to fight for equity. In the following three pairs of vignettes, examples for this subversive and empowering discourse will be given. The first two pairs have been published separately (they were put near each other in order to make a comparison), while the last pair constitutes a mini-strip.
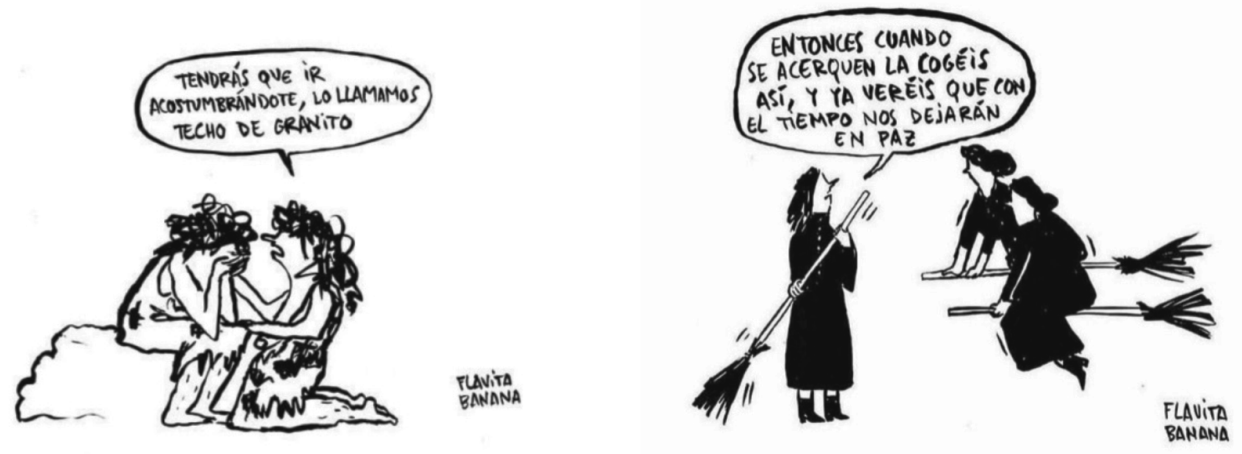

Sources: Instagram, @flavita.banana, 10 October 2018 // Instagram, @flavita.banana, 22 January 2020

Figure 4. You must learn to live with it, we call it granite ceiling.

Figure 5. Okay, so when they are approaching, you just grab it this way, you will see that as time passes, they will leave us be.

The first vignette represents two female figures wearing clothes that might seem familiar from the animation sitcom The Flintstones, so the reader might suppose the scene is taking place in prehistoric times. This is exactly the source of humour, together with the wordplay granite ceiling, which is clearly an "ancient" version of the concept glass ceiling, denoting the invisible barriers female professionals face when trying to achieve high positions at their workplace, in academia, or politics. The message of the vignette - patriarchy and the setbacks experienced by women are as old as Homo sapiens - is bitter, here laughter only serving self-irony and maybe solidarity with women from all ages. Compassion is incorporated in the figure of the wise friend, the character which is speaking in the vignette. Although she shows 
support towards her friend in distress, she only explains and confirms the situation. Her words do not show an alternative to the status quo and are not uplifting, which is visually represented by her kneeling position, suggesting passivity, surrender, and humiliation.

The second vignette also plays with the historical past of women. Witchcraft has represented independence and the power of women that escaped political and social control, while witch hunts wanted to repress exactly this freedom. This is a common topic of feminist non-fiction (Federici 2009), fiction (Kiran Millwood Hargrave's 2020 novel The Mercies), and documentary fiction alike (such as The Žítková Goddesses by Kateřina Tučková). Flavita Banana shows a typical feminist strategy of subversion: the witches in the illustration pretend to obey traditional gender norms, using their magical broomsticks for cleaning, and this mask of imitating the dominant discourse allows them to continue with their activities, express themselves the way they are. Here, in contrast with the surrendering position in the former vignette, the two witches floating on their broomsticks in the air symbolize a possibility of both uprising and overcoming the patriarchal status quo, flying freely. The feminist theoretician Barbara Godard gives the example of gossip, which is a form of peripheral discourse, marginalized by patriarchal society, yet it enables a rebellious and subversive discourse (Godard 1989). Similarly, as we have seen in the case of Jo Anna Isaak and Sabah Al Mushtaq, humour offers us the possibility to enter an ambiguous and playful space where we are allowed to imagine a different social order, maybe to invent strategies to escape both sexist oppression and the witch hunt.
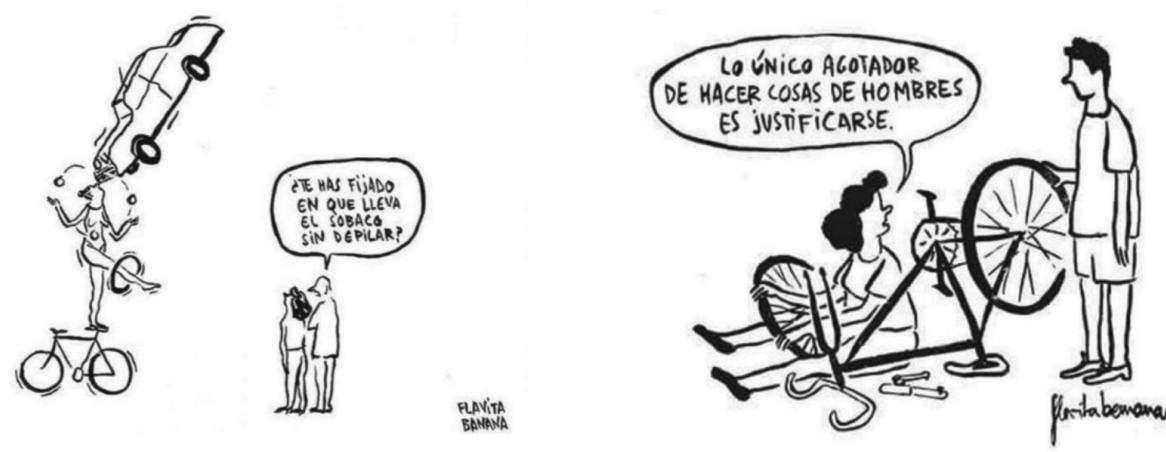

Sources: Instagram, @flavita.banana, 15 January 2020 // Instagram, @flavita.banana, 30 April 2019

Figure 6. Have you noticed that her armpit is not shaved?

Figure 7. The only exhausting thing in doing men's tasks is explaining myself. 
Here, in the first vignette, we see a woman balancing different objects in a complex manoeuvre, symbolically representing the women on whom there is an immense pressure to be perfect in both their professional and personal life, to fit into the roles of mothers, sisters, workers, wives, friends, etc. The man looking at her mentions something he considers a flaw on her body, her hairy armpit. It is a typical situation many women experience, that complete strangers comment on their bodies, but especially that they receive any kind of feedback only if there are errors in the results of their work (above all, in the case of reproductive work: Who has been complimented when the dishes are spotless, and how many times are there malicious comments if even one plate is greasy?). Again, we feel compassion for the female figure and fury towards the carrier of this male gaze. The source of humour is the discrepancy between what the reader sees in the illustration, beyond the male gaze (the multitasking woman), and what the character sees through his male gaze (something that he considers a flaw). His comment demonstrates that he only sees what he can and what he wants to see since there are some beauty standards that direct and influence the way he sees. In the imaginative space of humour, this is deconstructed, and we as readers are able to see why he sees the way he does and also to see more, to see in a different way. The male gaze is not only exposed, but we are offered an alternative to it. However, the female protagonist of the vignette might seem a victim, which is not an empowered position at all. Here, the artist depicts injustice, but in the next vignette she goes further, to an empowering approach. As Sabah Al Mushtaq mentions in her quoted article, feminist humour contains the positive evaluation of women, celebrates women's experiences, and asserts their strength, capabilities, and autonomy (2017: 35). The vignette represents a woman repairing a bicycle, traditionally considered a man's task, related to many experiences of mansplaining. The female protagonist of the vignette implicitly constates that there is no difference between women's and men's ability to fulfil certain tasks; she only seems irritated that she has to justify her actions. It is interesting to observe how some minimalist vignettes can depict female agency. Both of these examples represent women engaged in productive, creative, and efficient activities (repairing the bicycle, balancing with many objects), whereas the men are shown in idle states (especially the character playing with the bicycle's wheel). The aim here is not to humiliate men, only to highlight women's activity and also the position from which in the patriarchy superficial judgement is often so easily pronounced. In other words: the vignettes do not judge themselves but show the space and the mechanisms that perpetuate this kind of judgement. 

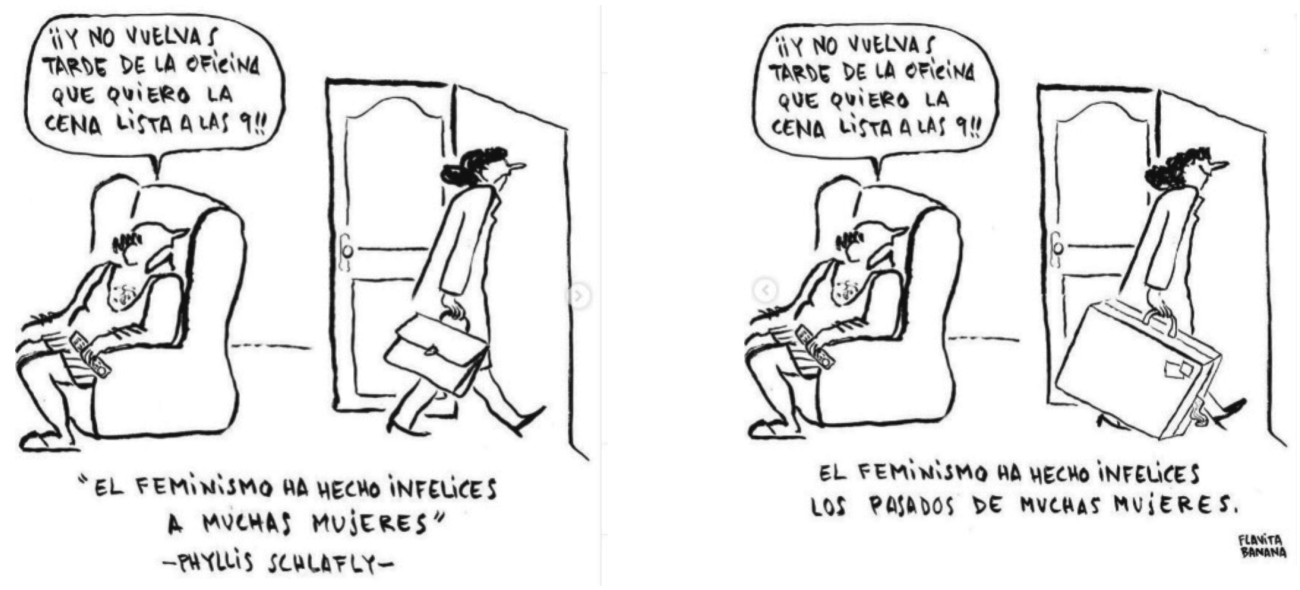

Source: Instagram, @flavita.banana, 29 April 2020

Figure 8. 1. - And don't dare to come back late from the office 'cause I want the dinner to be ready at 9 p.m. "Feminism has made many women unhappy." Phyllis Schlafly. 2. - And don't dare to come back late from the office "cause I want the dinner to be ready at 9 p.m. Feminism has made the past of many women unhappy.

This example deconstructs the stereotype that all men are misogynists and all women must be feminists. It suggests that it is time we left behind such binary-bound and shallow thinking. The two vignettes play with a quote from ultraconservative and antifeminist lawyer Phyllis Schlafly. There are only two small changes between the images: the protagonist's facial expression, suggesting at first irritation and sadness and then happiness, at first carrying a briefcase and later a suitcase. The modification of the quote also suggests the ability of the woman to leave her unhappy past behind and start a new life thanks to the shift produced by feminism. The manipulation of the quote is a typical strategy of subversive discourse.

Flavita Banana's humour is considered a balance between laughter and cry, as two Spanish scholars mention; her vignettes should be read twice: the first lecture is comic, the second one provoking a certain bitterness; the artist uses the amusing moment to encourage the reader to reflect and think critically (Del Río CastañedaBenito Temprano 2018: 44-47). Flavita Banana herself reflects on the role of humour. 


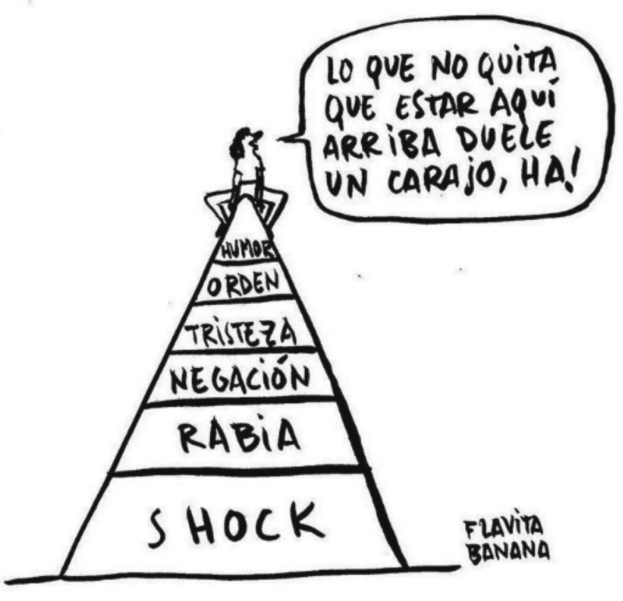

Source: Instagram, @flavita.banana, 13 March 2017

Figure 9. (From bottom to top): shock, fury, denial, sadness, order, humour. Which doesn't mean that being up here doesn't hurt as hell, ahh!

In this vignette, Flavita Banana depicts different emotions such as shock, fury, denial, or sadness. All these feelings are visually represented as the base of a mountain or the lower part of an iceberg, which is usually invisible under the surface of the water, while humour is the very tip of this structure. The female character is balancing on the top of this pyramid. Her sentence suggests that reaching the state of mind of acceptance, as a result of letting go other emotions and taking distance from the original situation, does not mean that humour makes all unpleasant parts of the reality invisible. On the contrary, it is rather associated with clear insight and a better knowledge of the world, as Flavita Banana expresses in an Instagram post (10 January 2020): "If you work with humour, it is because you think a lot. If you think a lot, you realize more things than happy people."

\section{Conclusions}

This paper has proposed a definition of humour as a safe and free space meant to imagine alternatives to the existing gender stereotypes and inequalities. In the analysis of Quino's and Flavita Banana's works, we could observe different strategies in the presentation of gender-related issues and different roles of humour. While Quino's Mafalda uses humour in order to expose sexism and injustice, the comic series cannot transgress stereotypes and confirms the status quo. Flavita Banana's vignettes depict empowered women, and therefore her humour is a means to imagine a more just world. 
Comics and vignettes with feminist content can draw attention to genderrelated issues. This is especially true in the case of these popular and accessible genres spread on social media. With the feminist issues currently on the agenda in Spanish-speaking countries, artworks such as Quino's Mafalda and Flavita Banana's vignettes can also contribute to raising awareness and constructing politically active citizenship.

\section{References}

Bilger, Audrey. 1998. Laughing feminism: Subversive comedy in Frances Burney, Maria Edgeworth, and Jane Austen. Detroit: Wayne State University Press.

Blanco, Martínez-Miguel, Ángel. 2017. La traducción desde la perspectiva de género. Una traslación de compromise del comic feminista contemporáneo del español al inglés [Translation from a gender perspective. A translation of social commitment applied to contemporary Spanish feminist comic books translated from Spanish to English]. In: Anne Bécart-Viviana Merola-Rafael López-Campos (eds.), Current approaches to translation and interpretation studies. Seville: Editorial Bienza. 19-26.

Cixous, Hélène. 1976. The laugh of the Medusa. Transl. by Keith Cohen-Paula Cohen. Signs 1(4): 875-893.

Cochrane, Kira. 2013. All the rebel women: Exclusive Guardian Shorts ebook extract. The Guardian December 16. https://www.theguardian.com/global/2013/ dec/16/all-the-rebel-women-guardian-shorts-ebook-extract (downloaded on: 4 May 2020).

Cosse, Isabella. 2014. Mafalda: historia social y política [Mafalda: Social and political history]. Buenos Aires: Fondo de Cultura Económica.

Del Río Castañeda, Laro-Benito Temprano, Claudia Sofía. 2018. Flavita Banana: Ilustración y microrrelato [Flavita Banana: Illustration and flash fiction], Microtextualidades. Revista internacional de microrrelato y minificción (3): 41-55.

Federici, Silvia. 2009. Caliban and the witch. Women, the body and primitive accumulation. Brooklyn: Autonomedia.

Foster, David William. 2004. Mafalda: An Argentina comic strip. The Journal of Popular Culture 14(3): 497-508.

García Navarro, Nerea, 2018. Pinceladas con nombre de mujer: El humor gráfico y sus ilustradoras [Brushstrokes with women's names: Graphic humour and its illustrators]. Aularia. El país de las aulas (1): 109-119.

Godard, Barbara. 1989. Theorizing feminist discourse / Translation. Tessera (6): 42-53.

Hargrave, Kiran Millwood. 2020. The Mercies. London: Picador. 
Kalviknes Bore, Inger-Lise-Graefer, Anne-Kilby, Allaina. 2017. This pussy grabs back: Humour, digital affects and women's protest. Open Cultural Studies (1): 529-540.

Mackie, Marlene. 1990. Who's laughing now? The role of humour in the social construction of gender. Atlantis 15(2): 11-26.

Marchionni, Franco-Sales, Romina Giselle. 2012. Mafalda reload. Aproximaciones conceptuales a la cultura latinoamericana a través de la obra de Quino [Mafalda reload. Conceptual approaches to Latin American culture through the work of Quino]. Registros. Revista de Investigación Histórica 8(8): 2-24.

Mushtaq, Sabah Al. 2017. Humour: As a tool for gender construction and deconstruction. International Journal for Intersectional Feminist Studies 3(1): 29-38.

Quino (Lavado Tejón, Joaquín Salvador). 1997. Toda Mafalda [Complete Mafalda]. $8^{\text {th }}$ edition. Buenos Aires: Ediciones de la Flor.

Tučková, Kateřina. 2012. Žítkovské bohyně [The Žítková Goddesses]. Brno: Host.

Wollstonecraft, Mary. 1796. A vindication of the rights of woman: With strictures on political and moral subjects. London. Facsimile edition 1996. Dover: Thrift Editions. 